\title{
A EXORTAÇÃO DO PODER PASTORAL NA EDUCAÇÃO DAS CRIANÇAS EM UM TRATADO DE ALEXANDRE DE GUSMÃO, AMÉRICA PORTUGUESA (SÉCULO XVII)
}

\author{
LA EXHORTACIÓN DEL PODER PASTORAL EN LA EDUCACIÓN DE LOS \\ NIÑOS EN UN TRATADO DE ALEXANDRE GUSMÃO, AMÉRICA PORTUGUESA \\ (SIGLO XVII)
}

\author{
THE EXHORTATION OF PASTORAL POWER IN THE EDUCATION OF \\ CHILDREN IN A TREATY OF ALEXANDRE GUSMÃO, PORTUGUESE AMERICA \\ (17 ${ }^{\text {TH }}$ CENTURY)
}

Fernando RIPE ${ }^{1}$

RESUMO: Neste artigo pretende-se, a partir das categorias conceituais vigilância e punição, analisar as estratégias que orientavam o processo de constituição dos sujeitos masculinos infantis, no contexto luso-brasileiro do final do seiscentos, presentes na obra Arte de crear bem os Filhos na idade da Puericia. Escrita na América portuguesa, mas publicada em Portugal no ano de 1685, a obra de autoria do padre jesuíta Alexandre de Gusmão (1629-1724) oferecia um elenco de normativas que definiam como se deveria formar um "perfeito menino". A partir de uma analítica foucaultiana identificamos nas prédicas do jesuíta uma incitação discursiva ao mecanismo do poder pastoral através de um conjunto de recomendações para os pais sobre a importância de vigiar as crianças e de como disciplinar e castigar estes meninos para se "bem crear".

PALAVRAS-CHAVE: Infância. Vigilância. Punição. Poder pastoral. Alexandre de Gusmão.

RESUMEN: Este artículo pretende, a partir de las categorías conceptuales de vigilancia y castigo, analizar las estrategias que orientaron el proceso de constituición de los sujetos masculinos de los niños en el contexto portugués-brasileño de finales de los seiscientos, presentes en la obra Arte de crear bem os Filhos na Idade da Puericia. Escrita en la América portuguesa, pero publicada por primera vez en Portugal en 1685, la obra escrita por el jesuita Alexandre de Gusmão (1629-1724) ofrecía una lista de reglamentos que definían cómo se debía formar un "chico perfecto". Desde un referencial de análisis de Foucault identificamos el jesuita predicando una incitación discursiva al mecanismo del poder pastoral a través de un conjunto de recomendaciones para los padres sobre la importancia de proteger a los niños y cómo disciplinar y castigar a estos niños para "crear bien".

${ }^{1}$ Universidade Federal de Pelotas (UFPel) - Pelotas - RS - Brasil. Doutorando no Programa de PósGraduação em Educação. Membro do Centro de Estudo e Investigação em História da Educação (CEIHE/UFPel). E-mail: fernandoripe@yahoo.com.br 
PALAVRAS CLAVE: Infancia. Vigilancia. Castigo. Poder pastoral. Alexandre de Gusmão.

ABSTRACT: This article is intended, from the conceptual surveillance and punishment categories, analyzing the strategies that guided the process of meeting the specific ways of being subject child male in Luso-Brazilian eighteenth-century context, prescribed in the work Arte de crear bem os Filhos na idade da Puericia. Written in Portuguese America, but first published in Portugal in 1685, the work written by the Jesuit Alexandre de Gusmão (1629-1724) offered a list of regulations that defined how one should form a "perfect boy. From a Foucaultian analysis we identify in the Jesuit's preaching a discursive incitement to the mechanism of pastoral power through a set of recommendations for parents on the importance of guarding children and how to discipline and punish these children to "create well."

KEYWORDS: Childhood. Surveillance. Punishment. Pastoral power. Alexandre de Gusmão.

\section{Introdução}

Os Egypcios, que tudo explicavam por Ieroglificos, para significarem a Deus pintavam hũa vara com hum olho na ponta, querendo dizer, que Deus neste mundo tudo via, \& tudo castigava: assim ha de ser o pay de filhos em sua casa, como he o pay universal em todo o mundo, olho, \& vara" (GUSMÃO, 1685, p. 310-111).

Olho e vara, a vigilância e a punição estas foram duas assertivas que se tornaram imperativas nos aconselhamentos de como se educar um perfeito menino cristão na obra Arte de crear bem os Filhos na idade da Puericia do padre português Alexandre de Gusmão (1629-1724). O impresso, que foi inicialmente publicado em Lisboa no ano de 1685, teve sua escrita na América portuguesa pelo religioso lisboeta Gusmão - um importante literato e ascético de relevantes obras para a literatura e para história educacional da colônia ${ }^{2}$-, consistia em um conjunto de prescrições edificantes e aconselhamentos espirituais de como os pais e os mestres, preocupados com a educação de meninos, deveriam guiar a conduta das crianças.

\footnotetext{
${ }^{2}$ Destaco duas pesquisas acadêmicas que abordaram, a partir de diferentes perspectivas, a biografia do jesuíta português Alexandre de Gusmão. Sugere-se: FREITAS, César Augusto Martins Miranda de. Alexandre de Gusmão: Da Literatura Jesuíta de Intervenção Social. Tese de Doutoramento. Doutorado em Literaturas e Culturas Românicas. Faculdade de Letras da Universidade do Porto. Porto: Universidade do Porto, 2011. SOUZA, Lais Viena de. Educados nas letras e guardados nos bons costumes. Os pueris na prédica do Padre Alexandre de Gusmão S.J. (séculos XVII e XVIII). 210f. Dissertação de Mestrado. Programa de PósGraduação em História da Universidade Federal da Bahia. Salvador: UFBA, 2008.
} 
A ideia contida na metáfora, anteriormente apresentada, foi elaborada pelas sociedades orientais antigas e trazia como referência a figura de um faraó egípcio, que, assim como o pastor cuidador de ovelhas, possui um cajado que lhe auxilia em suas tarefas, o que lhe conferia simbolicamente o título de "pastor dos homens" (FOUCAULT, 2003, p. 358). Sabe-se, a partir do filósofo francês Michel Foucault, que o exercício do poder pastoral de caráter religioso, fundamentalmente operado na cultura judaico-cristã e desenvolvido pelos hebreus, teve longa transformação no interior da instituição católica, desde o século III ao século XVII. Foucault ainda destacou quatro aspectos do poder pastoral que incidem sobre o governo da vida dos indivíduos e na condução à salvação: primeiro que o pastor desenvolve o poder sobre um rebanho (no caso do pai sobre sua família), mais do que sobre uma terra; Segundo, que o pastor reúne, guia e conduz seu rebanho, " o rebanho existe pela presença imediata e pela ação direta do pastor”; Terceiro, que o papel do pastor é o de assegurar a salvação de seu rebanho; Quarto, que o exercício do poder pastoral é um "dever", "A benevolência pastoral, em contrapartida, é muito mais próxima do "devotamento". Tudo o que o pastor faz é pelo bem de seu rebanho" (FOUCAULT, 2010, p. 360).

Em Arte de crear bem os Filhos, Alexandre de Gusmão priorizou fundamentalmente na sua escrita tanto os pecados cometidos pelos pais na má educação que dão para seus filhos, como aqueles praticados pelos pequenos “anjos", por consequência, também atenuava ênfases na prescrição de sanções e suplícios religiosos que os mesmos deveriam ter como forma de remissão. A ideia do pecado, essa possível desobediência a Deus e à Igreja, parecia regular a vida cotidiana das pessoas, de modo que o discurso partilhado por Gusmão direcionava espiritualmente o exercício do poder pastoral. A partir da incitação ao uso de específicas técnicas disciplinadoras do corpo pueril, como verificaremos ao longo do texto, identificamos que esse discurso intensificou a questão educativa sobre as crianças, promovendo lições morais e exemplificadoras que deram real destaque para particularidades acerca da moralidade e da religiosidade, desenvolvendo, assim, uma economia geral da obediência infantil no mundo luso-brasileiro no final do século XVII.

Nesse sentido é interessante observar que um conjunto de ditames morais foi utilizado pelo cristianismo no mundo romano como forma de introduzir novas técnicas para impor essa moral. Para Foucault (2006) essas técnicas serviram para impor "um conjunto de novos mecanismos de poder para inculcar esses novos imperativos morais" (p. 
65). Esse poder foi denominado como pastorado, a existência dentro da sociedade cristã do "papel de condutores, de pastores em relação a outros indivíduos que são como suas ovelhas ou o seu rebanho" (FOUCAULT, 2006, p. 65).

A Arte de criar bem os filhos na idade da puerícia foi a terceira obra publicada por Alexandre de Gusmão. O livro foi dividido em duas partes: a primeira, contém 19 capítulos que orientavam os fundamentos teológicos para a "boa educação" dos meninos; já, na segunda parte da obra, intitulada Como se ham de aver os Pays na creaçcam dos mininos prescrevem, através de 25 capítulos, aconselhamentos práticos e edificantes para que os pais educassem seus filhos. Ao longo de 387 páginas os ensinamentos são retomados várias vezes, seja pela demonstração de modelos exemplares, ou por representações assustadoras, ou mesmo, através da incitação à punição e o castigo como modos corretivos e disciplinadores da má criação.

Em se tratando do contexto de editoração da obra, a expressão arte quer designar "Regra, \& methodo, com cuja observaçaõ se fazem muitas obras uteis, agradáveis, \& necessarias à Republica" (BLUTEAU, 1728, p. 573). Outro significado dicionarístico para o termo é "Livros que se contém preceitos práticos" (SILVA, 1789, p. 199). A partir destas duas acepções identificamos a existência de uma constante produção literária no século XVII, e sobretudo nos séculos subsequentes, que dão regras, métodos e aconselhamentos práticos e espirituais de como educar as crianças. A historiadora Lais Viena de Souza elaborou sua dissertação de mestrado Educados nas letras e guardados nos bons costumes (2008) tendo como principal objeto de análise o padre jesuíta Alexandre de Gusmão, especialmente os seus discursos sobre a importância da educação e as recomendações para o "bem criar". Da mesma forma, a autora confere a análise do projeto pedagógico de Gusmão encerrado no Seminário de Belém da Cachoeira. ${ }^{3}$ Sobre a tipologia literária que particularizava a atenção e cuidado sobre a criança, a autora entendeu que

[...] no período moderno, o crescente interesse e a preocupação em dirimir a sociedade, em um amplo projeto de pedagogização. Nesse intuito, foram produzidos os manuais e tratados de essência pedagógica sobre temáticas diversas, que notadamente apresentavam a importância

\footnotetext{
${ }^{3}$ De acordo com Serafim Leite o Seminário de Belém da Cachoeira, no Recôncavo baiano, nasceu como demonstração prática do que P. Alexandre de Gusmão, seu fundador, explanara antes em duas obras. Sejam Escola de Belém, Jesus nascido no Presépio (1678) e, sete anos depois, Arte de Criar bem os filhos na idade da puerícia. Dedicado ao Menino de Belém, Jesu Nazareno (1685). "A ideia do Seminário apresentou-se ao começo com caráter popular, para nele se criarem os filhos dos moradores, sobretudo os pobres, que viviam no sertão, e poderem estudar não só os primeiros elementos de ler e escrever, mas também latim e música" (LEITE, 1945, p. 167).
} 
da educação da infância. Daí a importância nesses discursos em caracterizar a criança cada vez mais amiudada como "alunos" e "filhos", terminologia que engendrou na modernidade dois espaços fundamentais para o desenvolvimento (aqui entendido como crescimento natural e também em seu aspecto de aprendizado) da criança (SOUZA, 2015, p. 59).

Ainda que se tratando de uma permanência dos séculos anteriores ao XVII, três gêneros de literatura relativas às atenções despendidas sobre as crianças foram publicados ao longo do período moderno. Souza (2015) destacou se tratarem dos manuais de civilidade e pedagogia, dos "espelhos de príncipes" e dos tratados sobre a educação dos filhos. No primeiro gênero a autora acredita se tratar da formulação de "roteiros sobre o bem agir das crianças da nobreza e aristocracia”, onde se destacam obras como De civilitate morum puerilium (1530) de Erasmo de Rotterdam (1466-1536), Didactica Magna (versão checa 1627 e versão latina 1631), Escola da Infância (1642) e O Labirinto do Mundo e o Paraiso do Coração (1623) de Javn Amos Komensky (1592-1670). O segundo gênero tratar-se-ia de "guias descritivos de práticas e saberes necessários para a instrução do rei infante". E, por fim, o terceiro gênero sobre tratados que apresentam recomendações, prescrições e aconselhamentos aos pais e preceptores para que a educação das crianças fosse um processo de constante vigilância, poucas bajulações e ordenadas pelo recato e a decência. ${ }^{4}$ Nas centúrias do XVI e XVII também merecem destaque as obras de Michel de Montaigne (1533-1592) no ensaio Sobre a educação das crianças publicado em 1580, Francisco de Sales (1567-1622) no tratado religioso Filoteia ou Introdução à vida devota de 1609, João Batista de La Salle (1651-1719) com a obra Les régles de la bienséance et la civilité chrétienne da metade do século XVII e uma série de escritos sobre a arte de ensinar de Wolfgang Ratke (1571-1635).

\section{O saber religioso para regular o corpo infantil}

Registros escritos por religiosos e obras clericais podem ser percebidos como exemplos de publicações que colocaram luz a uma problemática central: a constituição, manutenção e uso dos bons comportamentos sociais para uma sociedade colonial luso-

${ }^{4}$ SOUZA, Laís Viena de. Educados nas letras e guardados nos bons costumes: Padre Alexandre de Gusmão S.J., infância e educação na Bahia Colonial. Salvador: EDUFBA, 2015, p. 47-54. 
brasileira cristã e civilizada. ${ }^{5}$ Então, nesse sentido, problematizar a constituição do comportamento infantil no período mencionado, além de ser de profícua relevância enquanto objeto para a investigação no campo da História da Educação, ${ }^{6}$ também nos possibilita conjecturar como o discurso cristão que propagava a exortação do poder pastoral esteve imerso, no período moderno, entre a Igreja Católica, a prática da educação de crianças e a produção de sujeitos infantis.

Além de prédicas estritamente religiosas, publicadas entre os séculos XVII e XVIII, foi crescente, nos domínios portugueses, a circulação de obras que se destinavam ao conjunto de saberes: primeiras letras, ensino da caligrafia e rudimentos da aritmética. Evidentemente que os aspectos doutrinários ocupavam lugar de destaque nestas obras em detrimento dos conhecimentos pedagógicos. No entanto, um volumoso tipo de publicação, escritos por filósofos, juristas, médicos e mestres, divulgavam além dos ideais cristãos da época, e também reproduziam discursivamente os modos sociais, morais e políticos sobre a infância virtuosa cristã. Para Alexandre de Gusmão (1685, p. 05) "Os Philosophos com suas sentenças; os Politicos com seus dictames; os Legisladores com seus preceitos; os Reys com seus decretos; os Magistrados com seu poder" reconhecem a importância da infância, de modo que "todos conspiram para persuadir aos pays, \& para entabolar nas Respublicas a boa creaçam dos mininos". Tais pensadores tinham o interesse de persuadir determinados valores cristãos, normas de comportamentos e virtudes pueris próximas aos padrões de conduta exclusivos da corte.

Ainda que, se considerarmos como limitada a prática da cultura de leitura e escrita neste período no Ocidente, o mercado editorial se beneficiou das publicações para um público que continha grandes expectativas relativas ao domínio das práticas normativas da nobreza e da alta burguesia. $^{7}$ Propagava-se, então, uma série de obras dedicadas à

${ }^{5}$ Para Norbert Elias, em $O$ Processo Civilizador o conceito de civilização está vinculado às transformações nos padrões sociais de auto-regulação, de aquisição de boas maneiras a partir da educação mútua promovida pelos homens. Ver: ELIAS, Norbert. O processo civilizador. Uma história dos costumes (vol.1). Rio de Janeiro: Jorge Zahar Ed., 1994.

${ }^{6}$ No campo da História da Educação verificamos a ocorrência de um similar estudo e com mesma fonte primária. Trata-se do texto da historiadora Lais Viena de Souza (2006), Má Educação e Maus Exemplos: O Discurso Pedagógico-Moral Do Padre Alexandre de Gusmão S. J. (1629-1724). Nele a autora analisou as admoestações e amedrontamentos que o padre Alexandre de Gusmão realizou, na obra em questão, para exemplificar as possíveis penas que os meninos pagavam por seus maus autos, ou antagonicamente "a enlevação e as gratificações dadas aos que tinham comportamento virtuoso" (SOUZA, 2006).

${ }^{7}$ Eliane Fleck e Mauro Dillmann (2014), no artigo Escrita, prática de leitura e circulação de manuais de devoção entre Portugal e Brasil nos séculos XVIII e XIX, compreendem que a significativa produção, edição e circulação de livros piedoso entre o percurso Atlântico foram decorrentes da existência de um público letrado que atribuía importância à literatura religiosa, de modo que assumiam como meios de orientação das condutas morais e devocionais os preceitos que eram pregados aos fiéis católicos. 
civilidade, cortesia e à polidez. Entretanto, vale lembrar a argumentação de Jacques Revel (1991, p. 176) de que as publicações destes conjuntos de normativas civilizatórias tenderam a "disciplinar as almas por meio da coerção exercida sobre os corpos e impor à coletividade das crianças uma mesma norma de comportamento sociável". Todavia as práticas coercitivas impostas para o disciplinamento das crianças eram carregadas de castigos, punições e constantes vigilâncias. Nesse sentido que a obra selecionada para análise ganha destaque como exemplo desse tipo de publicação ${ }^{8}$ em língua portuguesa que circulou nos principais domínios de Portugal, entre os séculos XVII e XVIII.

Renato Venâncio e Jânia Ramos, organizadores da reedição de Arte de bem criar os Filhos (2004), mencionam que a obra não se trata de um testemunho da sociedade colonial portuguesa na América, mas sim de um projeto de reformação da mesma. Parece-nos que este projeto surge pela constatação de Gusmão e de uma concepção europeia em relação à América, que seria marcada pela ausência de civilidade e pela presença de modos e comportamentos libertinosos e despudorados dos que aqui habitavam. Nesse sentido, é bastante interessante observar que um manual dedicado à boa educação das crianças ganhasse relativo sucesso entre os pais leitores mais preocupados com a formação cristã dos filhos, momento em que eram exclusivamente dos adultos a "responsabilidade pelos desvios e maus comportamentos das novas gerações" (VENÂNCIO; RAMOS, 2004, p. $\mathrm{XX)}$.

Na América portuguesa constata-se o predomínio da Companhia de Jesus na atuação educacional, na prescrição dos modelos pedagógicos e no direcionamento da formação de hábitos e condutas infantis. A condução da educação baseada na prática religiosa, sobretudo, nos escritos bíblicos e nas normas de bons costumes descritos na Constituição da Companhia de Jesus (2004 [1685]), evidenciou um conjunto de mecanismos disciplinadores regidos por prédicas morais cristãs, em que o castigo e a punição eram percebidos como modo de incutir temor àqueles para quem não bastavam as boas palavras e repreensões (CONSTITUIÇÃO DA COMPANHIA DE JESUS, 2004, p. 147).

${ }^{8}$ Destacamos as seguintes: do oratoriano Manoel Bernardes (1664-1710) Discursos sobre a Educação, de 1722; Apontamentos para a educação de hum menino nobre (1734) do fidalgo Martinho de Mendonça de Pina e de Proença (1693-1743); por fim, Cartas sobre a Educação da Mocidade (1750), do médico António Nunes Ribeiro Sanches (1699-1783), primeira obra que teve por intenção organizar um sistema de pedagogia mais escolar. A estes, somam-se outros manuais escritos por significativos pensadores, em sua maioria, inspirados nas publicações do final do seiscentos, que foram amplamente divulgados na Europa e tornaramse referência para a construção de modelos de educação, entre os quais, cabe destacar François Fénelon, John Locke, Michel Rollin e, ainda que censurado no mundo luso, o filósofo Jean-Jacques Rousseau. 
Em 1875 foi publicado em Paris um exemplar de Essai sur l'Iconographie de la Compagnie de Jesus do jesuíta francês Alfred Hamy, em comemoração aos três séculos e meio da Ordem inaciana, descrevendo a vida de quatrocentos reconhecidos jesuítas. Tendo o padre lisboeta Alexandre de Gusmão ocupado lugar dentre estes. Em 1893 o autor francês publicou uma coleção de retratos em Galerie illustrée de la Compagnie de Jésus : album de 400 portraits choisis parmi les plus beaux, les plus rares ou les plus importants, et reproduits en héliogravure, onde também consta uma imagem de Alexandre de Gusmão, como podemos verificar na Imagem 1 que ilustra o jesuíta em uma biblioteca ensinando o catolicismo para crianças, uma evidente representação da sua primeira obra Escola de Belém, Jesus nascido no Presépio publicação de 1678 em Évora.

\section{Imagem 1: Representação do padre Alexandre de Gusmão}

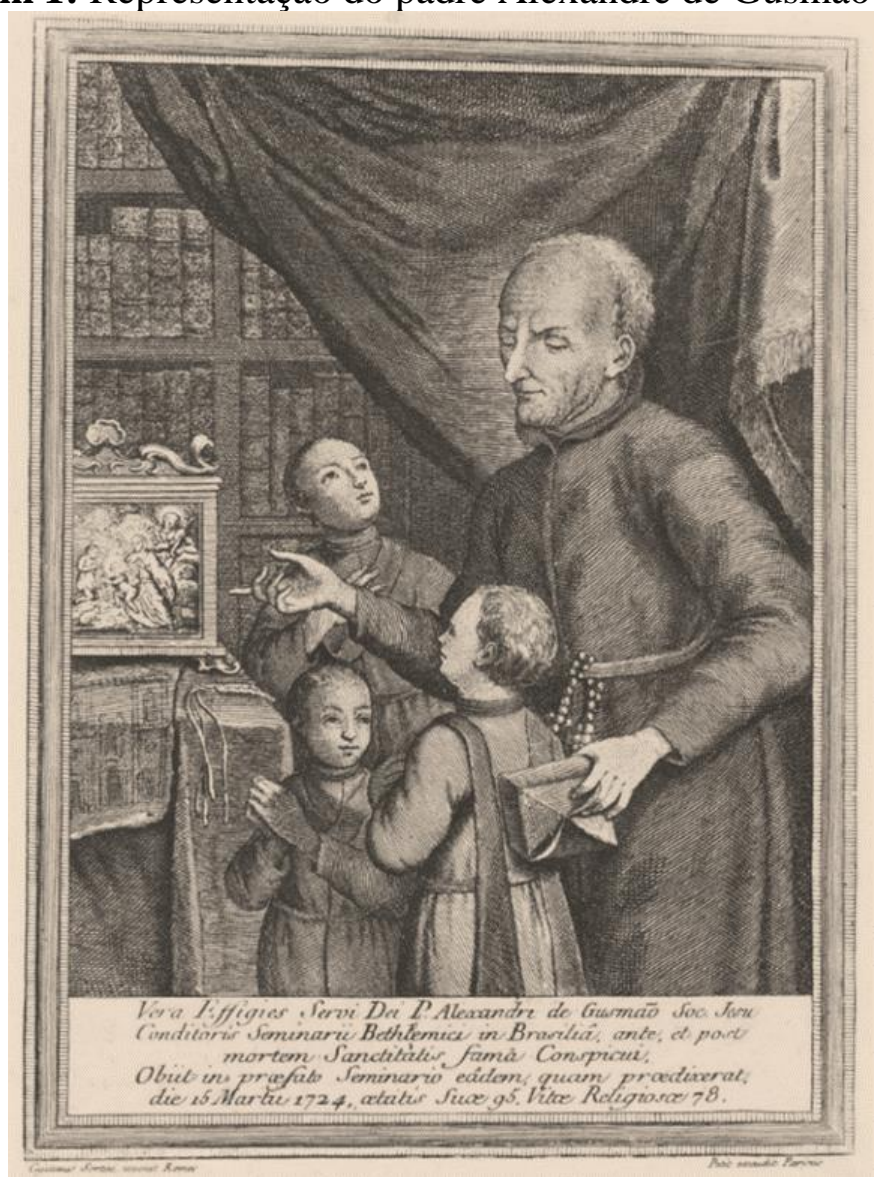

Fonte: HAMY - Galerie illustrée de la Compagnie de Jésus [...] (1893). ${ }^{9}$

${ }^{9}$ Possivelmente esta representação foi realizada no século XIX, tendo sido assinada por Cajctonus Sortini (s.d.). Disponível em

<http://www.europeana.eu/portal/record/9200134/BibliographicResource_2000000014696.html>. Acesso em: 11 fev. 2016. 
Então, a partir deste contexto da expansão da cultura escrita e da produção de sujeitos infantis, com comportamentos sociais e morais desejáveis, guiados pelos preceitos cristãos da Companhia de Jesus, que nos propomos analisar um conjunto de enunciados sobre disciplinamento na obra Arte de crear bem os Filhos na idade da Puericia onde se destacam como imperativos, por sua recorrência, as prescrições para a constante vigilância sobre as ações das crianças e as práticas de punição ao meninos desobedientes, ou mesmo, como forma de acautelar um possível desvio de conduta infantil. Este tipo de operação punitiva e moralizadora intentava evitar que o menino caísse em pecados e desobediências aos pais. Estas ações eram tidas como legítimas e adequadas na construção de discursos que desejam produzir um sujeito infantil obediente, disciplinado, virtuosamente cristão e moralmente guiados pelos bons costumes.

A análise da obra de Gusmão indicou a promoção do controle do corpo e da aparência através de práticas disciplinadoras, que se constituem como dispositivos ${ }^{10}$ normativos e modeladores dos comportamentos sociais pueris empregados à época e que eram propagados discursivamente através de uma tipologia literária específica. Ao operar com a divulgação dessas práticas disciplinadoras da vigilância e da punição Gusmão sintetizou um modelo prescritivo de sujeito infantil. Vale destacar que a ordem desses preceitos é importante, pois ao contrário do poder soberano, que manifestava sua força a partir da punição, na disciplina a vigilância antecede à punição, pois trata-se do exercício de um poder que busca o máximo de eficiência na interiorização da disciplina.

A partir de uma analítica foucaultiana identificamos que o processo de prescrições discursivas, que organizavam os modos de ser um menino cristão luso-brasileiro no seiscentos, a partir do arranjo interno da Igreja (entenda-se Companhia de Jesus) e mobilizado na narrativa de escritores, incitaram um minucioso processo de fabricação individual disciplinar do sujeito infantil. Esse processo de produção de sujeitos torna-se eficiente na medida em que se adotam uma série de regulações dos espaços, cerceamento das práticas e permanente olhar sobre as condutas do sujeito. Segundo Michel Foucault:

Cada indivíduo no seu lugar: em cada lugar, um indivíduo. Evitar as distribuições por grupos, decompor as implantações coletivas; analisar as pluralidades confusas, maciças ou fugidias. $\mathrm{O}$ espaço disciplinar tende a se

${ }^{10}$ A noção de dispositivo, proposição do pensador francês Michel Foucault, possibilita a compreensão dos processos de normatização postos pelo discurso da modernidade. Foucault utilizou como ferramenta analítica a noção de dispositivo como sendo um determinado agrupamento de práticas, que constituem o sujeito em meio a uma trama de saberes e. Ver: FOUCAULT, Michel. História da Sexualidade: a vontade saber. 14 ed. Rio de Janeiro: Graal, 2001, p. 135. 
dividir em tantas parcelas quanto corpos ou elementos há a repartir. É preciso anular os efeitos das repartições indecisas, o desaparecimento descontrolado dos indivíduos, sua circulação difusa, sua coagulação inutilizável e perigosa; tática de antideserção, de antivadiagem, de antiaglomeração. Importa estabelecer as presenças e ausências, saber onde e como encontrar os indivíduos, instaurar as comunicações úteis, interromper as outras, poder a cada instante vigiar o comportamento de cada um, apreciá-lo, sancioná-lo, medir as qualidades ou méritos. Procedimentos, portanto, para conhecer, dominar e utilizar. A disciplina organiza um espaço analítico (FOUCAULT, 1997, p. 131).

Portanto, compreendemos a prática da disciplina como sendo um mecanismo de poder, cuja intenção é regular o comportamento do sujeito (infantil) aos padrões sociais desejáveis. Este processo de regulação é estrategicamente pensado a partir de um sistemático controle do espaço (por exemplo os agrupamentos de acampamentos, as modernas arquiteturas escolares, prisionais, hospitalares, etc.), do controle do tempo (a criação de rotinas, estabelecimento de horários) e da promoção de comportamentos moderados e aceitos socialmente (gestos, postura, brincadeiras, etc.). Todavia, este processo de disciplinamento é reforçado por um complexo sistema de vigilância.

No que se refere a disciplina colocada em funcionamento pela doutrina cristã das virtudes, identificamos que tais práticas buscavam promover o assujeitamento e acolhimento das crianças a um conjunto muito específico de virtudes morais (a prudência, a fortaleza, a temperança, a justiça) associadas com as virtudes que regulavam as relações entre os sujeitos cristãos (o respeito, o trato, a responsabilidade) e as virtudes teológicas (fé, esperança, caridade). Não obstante, podemos identificar a moral como sendo uma forma de comportamento em que o indivíduo se torna sujeito a partir das normas e deveres estabelecidos e sancionados pela Igreja.

Foucault chama de moral o amplo campo da problematização da conduta. Afirma que em toda moral há, pelo menos, três elementos que se articulam com uma relativa autonomia: o código moral, que prescreve as regras de conduta; a moralidade dos comportamentos, que é a conduta que se pode medir por aquelas regras e a ética, caracterizada pelas modalidades de relação consigo estabelecidas pelo sujeito moral quando segue uma ou outra regra (CANDIOTTO, 2013, p. 221).

Por sua vez, as técnicas disciplinares, ${ }^{11}$ que atuavam diretamente sobre os corpos dos indivíduos, eram compostas por um conjunto de dispositivos de poder e de saber, com

11 Ainda, de acordo com Michel Foucault, a disciplina que garantiria o controle dos corpos - visando sua docilidade, tornando-os úteis e produtivos, submissos e obedientes - produz ferramentas para compreendermos o processo de construção da normatização das condutas, que se dão sempre imersos nas 
base na vigilância hierárquica permanente da rotina do menino cristão, com vistas à normalização do seu comportamento. Nesse sentido, os constantes enunciáveis de Gusmão que atribuem à família, e mais especificamente ao pai, como responsável pela educação infantil ganharam real importância, o de implementar esses mecanismos normalizadores, ${ }^{12}$ tornando as crianças sujeitos dóceis, de comportamento social desejável - atitudes polidas nas relações sociais, tanto no âmbito público, como privado, ${ }^{13}$ cuidados com as aparências do corpo (os gestos, as expressões faciais, a limpeza) e dos modos de vestir (visto que estes, revelam ou escondem a posição social), de se portar à mesa, o completo domínio dos rituais de cortesias e etiquetas nas sociabilidades públicas características da nobreza e da alta burguesia. Gusmão firmava ser importantes estes compromissos na educação de crianças e apresentou já no direcionamento ao leitor que o intuito da obra era "ensinar as boas artes, \& inculcar os bons costumes" (GUSMÃO, 1685, Prólogo). O historiador francês Roger Chartier, ao indagar que era "obrigatório controlar as emoções e dominar os impulsos, distanciar-se do corpo e aumentar o nível de recato, transformando preceitos em comportamentos, normas em habitus e escritos em práticas" reforça o indicativo de que os discursos sobre comportamentos sociais desejáveis era uma prática constante na literatura moderna (CHARTIER, 2014, p. 29).

\section{'Olho, \& vara': análise dos imperativos da vigilância e da punição}

Dois enunciados foram recorrentemente manifestados na obra de Alexandre de Gusmão, dando o tom de como "hum pay deve crear" seus filhos para uma vida virtuosa e edificante. Estes enunciados foram aqui tomados como unidades de sentido para compreender a exortação de um modelo prescritivo para o exercício do poder pastoral. A pesquisadora em Educação Rosa Maria Fischer acredita que a hipótese levantada por Foucault acerca do poder pastoral "consiste em criar e incentivar uma série de procedimentos, ligados a um objetivo último: a salvação individual” (FISCHER, 1999, p.

relações de poder, "constrói quadros; prescreve manobras; impõe exercícios; enfim, para realizar a combinação das forças, organiza "táticas"” (FOUCAULT, 1997, p. 150).

${ }^{12}$ Foucault definiu sociedade de normalização como sendo aquela em que se cruzam a norma da disciplina e a da regulamentação, através de tecnologias de poder que cobrem toda a vida, do corpo humano ao coletivo. FOUCAULT, Michel. Em Defesa da Sociedade: curso no Collège de France (1975-1976). São Paulo: Martins Fontes, 2005. p. 302.

${ }^{13}$ Sugere-se: REVEL, J. As práticas de civilidade. In: ARIÉS, Philippe. DUBY, Georges, D. História da vida privada: Do Renascimento ao Século das Luzes, V. 3. São Paulo: Companhia das Letras, 2009. 
47). Deste modo, destacamos que como estratégias para a constituição dos sujeitos masculinos infantis a prática da vigilância e da punição tornaram-se imperativas no processo de educação das crianças, na medida que lhe propunha sua "salvação".

A prática da vigilância foi incitada a partir de dois claros objetivos: não afastar as crianças da assistência espiritual cristã e evitar que o menino caísse em desobediência. Nesse sentido, a exortação ao poder pastoral, evidenciada mais especificamente, nos usos dos dispositivos de vigilância e de punição, corrobora para diminuir as possíveis potências dos infantis, ao mesmo tempo em que estabelece estratégias para a contenção dos sujeitos desviantes, "Posto que de todo o pecado devem os pays afastar os filhos, em quanto sam mininos". Para Gusmão o exercício da vigilância dos pais também é era uma forma de controle para o menino não cair em desonestidade, "vigiando como a Aguia sobre eles, para que nam sejam mordidos nos primeiros anos de tam peçonhenta víbora" (GUSMÃO, 1685, p. 227). Ainda de acordo com o religioso, "Do qual se colhe a vigilância, que devem ter os pays sobre os filhos de pouca idade, examinando as companhias com que conversam, procurando com todo o cuidado, que de nenhũa sorte acompanhem com moços de máos costumes" (GUSMÃO, 1685, p. 252).

Ao ter o domínio das atividades da criança observadas "o pay vigilante, que he pastor de seu rebanho, ou que sabe governar sua família, faz como o experimentado pastor, que larga o gado do curral, nam quando quer, senam quando couvem". A plena vigilância deve ser constante e sobre todos aqueles que o pastor cuida, pois há aqueles pais "que sem cautela abrem francamente as portas aos filhos, para irem livremente onde querem [...]. Saem de casa seus filhos piqueninos para os jogos, \& desenfados pueris, como os cabritos, ou borregos, quando saem para o pasto do curral” (GUSMÃO, 1685, p. 220-221). Para Michel Foucault o tema da vigilância recebe grande importância no exercício do poder pastoral, na medida que

Ele faz ressaltar dois aspectos do devotamento do pastor. Em primeiro lugar, ele age, trabalha e contrai despesas para aqueles que ele alimenta e estão dormindo. Em segundo lugar, ele vela por eles. Ele presta atenção em todos, sem perder de vista nenhum deles (FOUCAULT, 2010, p. 360).

Para Alexandre de Gusmão a prática da vigilância também tem por finalidade o cuidado espiritual sobre a criança: 
[...] digo que em tres cousas principalmente devem vigiar os pays, em quanto os filhos sam infantes: primeira, guardalos das Bautismo; segunda, que se bautisem a tempo, \& com a solenidade, \& boa eleiçam de padrinhos, que a Igreja costuma. Terceira, quando for possivel criem as mays os filhos a seus peitos, \& quando por justas causas nam possam estas, tenham grande escolha na eleiçam das amas" (GUSMÃO, 1685, p. 171-172).

Alexandre de Gusmão ao exemplificar que os filhos são como pedras preciosas orientou aos pais que o mesmo cuidado que se tem sobre as valiosas joias "se ha de ter dos filhos pequenos; \& a mesma vigilancia, que se tem sobre as pedras preciosas, se ha de ter sobre os filhos mininos" (GUSMÃO, 1685, p. 11). Claramente o jesuíta valorizava em seu discurso os modos de cuidar os sujeitos infantis masculinos, ocupando pouquíssimo espaço as preocupações relativas às crianças meninas. ${ }^{14}$ Da mesma maneira, os meninos também foram comparados com frágeis flores, "porq' assim como as plantas, quânto mais nova he, tanto mais necessidade tem da vigilância o agricultor, assim os filhos, quanto mais mininos mais necessitam da vigilancia dos pays, \& da cultura dos mestres" (GUSMÃO, 1685, p. 13). A intenção desta constante vigilância era, sobretudo, proteger o filho menino do acometimento de alguns possíveis pecados como "Mentir, furtar cousas meudas, jurar, chamar nomes, falar palavras deshonestas" e preservá-los longe da imoralidade, mantendoos castos e inocentes (GUSMÃO, 1685, p. 227). ${ }^{15}$

As crianças desde "meudas" deveriam ser doutrinadas a temer as devidas punições para seus possíveis pecados ou desobediência, ainda que não houvesse real necessidade para os açoites, pois o castigo também era uma prática preventiva. $\mathrm{O}$ açoite, no contexto analisado, foi referido por Raphael Bluteau (1638-1734) como sendo um "Molho de varas, correa, disciplina, ou outra cousa semelhante, com que se castiga" (BLUTEAU, 1716, p. 105). Todavia essa prática punitiva exortada pelo poder pastoral, e exercido pelo pai, não tinha por intenção o mal para a criança, "sua principal função é fazer o bem em relação àqueles de que cuida" (FOUCAULT, 2002, p. 66).

${ }^{14}$ Sobre a educação de meninas, Alexandre de Gusmão não conferiu a mesma preocupação. O principal conselho do jesuíta Gusmão para a educação das meninas se dava na orientação do recolhimento doméstico, onde todos os familiares e criados deveriam se preocupar com sua guarda.

${ }^{15}$ Sobre a sexualidade infantil e a incitação à castidade presentes na obra de Alexandre de Gusmão sugere-se: RIPE, Fernando. "Do amor da castidade, \& horror a toda torpeza, com que se deve crear os mininos": análise do imperativo da inocência infantil em uma obra do Padre Alexandre de Gusmão. Revista Brasileira de História \& Ciências Sociais, v. 8, p. 08-31, 2016; RIPE, Fernando. Foi quando "se esquecèo das cousas de piedade, \& se depravou no torpe vicio": a sexualidade infantil e a incitação à castidade na obra do padre Alexandre de Gusmão, América lusa (século XVII). Anais do II Seminário Internacional Michel Foucault: Cinquentenário de As Palavras e as coisas. Volume II. Pelotas: NEPFIL UFPel, 2016. p. 96-116 
A dimensão do castigo foi colocada por Gusmão como algo em que não se pode fugir, pois não apenas os meninos de condutas desviantes, impróprias, desrespeitosas, mas também os pais que se negligenciam com a boa educação de seus filhos, deveriam ser castigados. Neste caso o perdúrio da punição podia acompanhar, tanto pais, como filhos por longínquo tempo, "não he muito os castigue Deos muy rigorosamente nesta, \& na outra vida" (GUSMÃO, 1685, p. 52). Para Gusmão:

O primeiro castigo com que Deos, na outra, começa a castigar estes pays, he o descuido, ou impiedade, com que seus filhos nesta se esquecem das almas de seus pays, deixando-os padecer terribilissimos tormentos [...] hum severo castigo de pays tão negligentes [...] [que] haviam faltado aos filhos com o ensino no tempo de maior necessidade, qual he o da puericia" (GUSMÃO, 1685, p. 55-56).

A sentença castigo figura no tratado em setenta e nove casos de recorrência, superior aos vocábulos relativos ao amor paterno e materno (VENÂNCIO; RAMOS, 2004). Este fato pode ser compreendido como um possível indicativo de quanto o padre jesuíta dedicou o mecanismo da punição para as ações corretivas e repreensivas na educação das crianças. Na concepção de Gusmão a prática de disciplinamento é correlata a da punição, visto que "disciplina significa aquela doutrina com que por meio do castigo o pay morigera o filho, ou o mestre, o discipulo" (GUSMÃO, 1685, p. 67).

Para Gusmão há uma forte distinção nas responsabilizações para a educação da criança, "o pai está mais obrigado à correção e a mãe à direção".

[...] o amor do pay é mais forte, \& o da mãy mais doce; conforme esses amores são tambem as doutrinas dos pays para com os filhos, os pays ensinam os filhos com mais severidade, porque os amam com mais força, e as mãys ensinam com mais suavidade, porque os amam com mais doçura" (GUSMÃO, 1685, p. 77).

Fazem parte do desenvolvimento da disciplina das crianças "os offícios de mestre, ayo \& tutor sejam differentes no cuidado, sam o mesmo na obrigaçam" (GUSMÃO, 1685, p. 82). A importância desta ocupação dos mestres, aios e tutores persiste no "cuidado de moderar, \& corrigir os procedimentos dos discipulos". Ainda que se atente para os excessos, suas principais funções punitivas são as provocações aos sentimentos de medo. Para Gusmão "os principaes documentos que os mestres \& ayos devem ensinar aos mininos he o medo, \& o valor, o medo da culpa, \& o valor para a virtude" (GUSMÃO, 1685 , p. 83-87). 
A introjeção da culpa e a incitação ao medo, tanto para os meninos de má educação, como para os pais negligentes, é exemplificada por uma série de possíveis sanções. Destacamos alguns perigos eminentes que, pais e filhos, estariam sujeitos, como a possibilidade de mortes repentinas e desastrosas, o temor da proximidade com o demônio e o inferno enquanto tormento eterno. Gusmão também exemplificou casos em que meninos de atos impudicos tiveram a morte como castigo para seus graves pecados.

Ainda que a expressão castigo seja uma categoria recorrente em toda a obra de Alexandre de Gusmão, o jesuíta dedicou atenção, em especial, a dois capítulos do seu tratado para arguir, especificamente, sobre as práticas punitivas, com os seguintes títulos: Cap. XVII. Quanto importa castigar os meninos quando erram e Cap. XVIII. Que não devem ser demasiadamente severos os pais nos castigos dos meninos. O primeiro prescreve o castigo enquanto uma prática "positiva" para a boa educação. Diversos exemplos procuram dar conta de que a vigilância e o castigo fossem importantes mecanismos educativos para livrar a alma do menino desarrazoado do inferno, "se os açoutares com a vara, não morrerá, e, dando-lhe com a vara, livrarás sua alma do inferno". Esse modelo disciplinador associa, novamente, a ideia de que não há disciplina sem castigo, "o mesmo he ensinar que castigar". Verificamos no excerto: "Assim como nam ha doutrina sem disciplina, nam ha criaçam boa sem castigo (...) o que nam castiga ao filho, aborrece-o, e o que ama, ensina-o como se fosse o mesmo castigar ao filho que ensinalo". E os rabinos entendiam minuciosamente essa assertiva, pois "diziam que a primeira cousa que aviam de fazer os pays, logo em amanhecendo, era dar a cada filho hũa surra de assoutes, para que, com aquella lembrança, gastasse todo o dia bem" (GUSMÃO, 1685, p. 309-312). Em suma, na prédica de Gusmão, a prática do castigo é um ato de benevolência, de afeto e cuidado no criar o filho, todavia não se deve o pai deixar-se levar por compaixão e ter misericórdia ao açoitar o menino.

Do qual se conclue a importancia de crear os meninos com o castigo, quando erram, \& que em os castigar procuram seu bem, \& lhes mostram maior amor, do que tratando-os com demaziada benevolência, castigandoos os emendam, \& fazem melhores; dissimulando seus erros os perdem; ou fazem peiores; corrigindo-os fazem oficio de pays, perdoandolhes, de tyranos; em os castigar imitam melhor a naturesa do pay de todos, que he Deos. (...) nam se deve mover facilmente o pay das lagrimas do filho, nem dos escarceos que faz o minino á vista do assoute para lhe perdoar, porque essa compaixam seria crueldade, \& nam amor. E mais val vello agora chorar com emenda, que chorallo depois com sua perdiçam (GUSMÃ̃, 1685, p. 316-317). 
No segundo capítulo, Gusmão alertou para os "pays mais severos ou menos prudentes" que para criar bem os meninos era necessário corrigir lhes, porém que não se exceda e contenha os "impetos da ira". Nesse sentido, "ainda que he de tanta importancia o castigo dos mininos a seu tempo, naõ devem com tudo ser os pays, nem os mestres, tam severos em os castigar que os exasperem, \& façam com isso peiores" (GUSMÃO, 1685, p. 319). A consequência dos possíveis castigos abusivos seria, além da possível fomentação à ira, o sufocamento ao "bom natural". Ainda como reprimenda "a demasiada severidade, ou a muita frequencia na reprehençam lhes faz perder o pejo ao peccado, com que se vem a desavergonhar mais, \& fazer peiores, naõ menos que com demasiada dissimulação, ou negligente correçam" (GUSMÃO, 1685, p. 323). Outra prescrição relativa ao castigo é que se evite "desordens", assim deve-se evitar que os açoites não sejam realizados no momento da infração do filho, mas "he bom conselho naõ castigar os filhos no flagrante delito, quando a deformidade da culpa naturalmente altera a cólera, \& faz romper em impetos de ira; senam guardarlhe o castigo para a noite, ou para a madrugada", porque "de madrugada estam os humores mais quietos (...) está o ânimo mais socegado para castigar com o rigor que pede o delito, \& nam com o excesso a que obriga a colera" (GUSMÃO, 1685, p. 323).

Por fim, Alexandre de Gusmão chamou a atenção dos pais para que os castigos açoites aplicados com "a vara, a disciplina ou palmatoria" - e as repreensões - gritos, aturdios, estrúgios - sejam moderados, pois é preciso "temperar o rigor com o amor, \& com a brandura a severidade", pois "assim como o assoute ao seu tempo livra a alma do minino da morte (...), esta demasiada severidade he causa de sua perdiçam” (GUSMÃo, 2004, p. 250).

\section{Considerações finais}

A metáfora egípcia sobre a vara com olho, contada por Gusmão e que foi lançada no início do presente texto, foi repetida pelo jesuíta ao descrever uma resposta do profeta Jeremias para Deus:

Vejo Senhor hũa vara vigilante, hũa vara com olhos; pois viste bem, disse o Senhor, porque assim hey de ser eu na execuçam de tudo o que te ordenar. De sorte que o que Deus nosso Senhor he em seu povo, há de ser o pay em sua família; vara vigilantes, ha de andar sempre com os olhos sobre os filhos, \& corrigir seus defeitos com a vara do castigo, \& este ha 
de ser seu primeiro cuidado na educaçam dos filhos, vigialos, \& castigalos (GUSMÃO, 1685, p. 312).

Para o filósofo Michel Foucault o exercício do "poder pastoral foi uma prática própria das comunidades monásticas que teve um importante desenvolvimento na literatura cristã dos primeiros séculos" e, que sobretudo, foram reativadas pelos ordenamentos religiosos nos constantes movimentos contra reformistas do século XVI (CASTRO, 2009, p. 329). Vale ressaltar o fato de que a infância se tornou objeto indispensável nos discursos religiosos do século XVII, evidenciado pelo fato da Igreja da Reforma Católica ter elencado a família como lugar privilegiado para a formação cristã. Nesse sentido as crianças tornaram-se uma espécie de "tábua da salvação da humanidade", cuja transformação e redenção durante a menor idade possibilitaria posteriormente, na idade da razão, adultos úteis e obedientes (VENÂNCIO; RAMOS, 2004, p. 10). Esse empreendimento em muito estava associado com a cultura escolar jesuítica do século XVII, que fora sistematizada e ordenada pelo Ratio Studiorum Institutio Societatis Jesu, publicado inicialmente em 1559. ${ }^{16}$ Esse conjunto de normas e práticas postos pela Companhia de Jesus definiam processos moralizadores sociais e estabeleciam saberes que deveriam ser ensinados, na prescrição de certos ditames práticos da vivência de corte.

A partir das prédicas do jesuíta Alexandre de Gusmão, identificamos uma série de enunciáveis que incitaram os pais no arranjamento do mecanismo do poder pastoral. Estes enunciáveis compunham um conjunto de recomendações sobre a importância de vigiar as crianças e de como disciplina-las através de açoites e castigos. Desta forma, compreendemos, a partir de uma analítica foucaultiana, que o uso do mecanismo do poder pastoral tinha por finalidade atuar na produção de subjetividades, no governamento das almas e no gerenciamento da vida infantil, criando sujeitos disciplinados e obedientes. A partir da recomendação de variadas técnicas disciplinares, identificamos que os pais deveriam corrigir, amedrontar, cercear, separar, entre outras práticas individualizantes, para conhecer a fundo seus filhos.

[...] no poder pastoral, ao contrário, o pastor serve ao rebanho, cuidando da vida de cada ovelha. O pastor se sacrifica pelo rebanho. Suas atitudes têm como finalidade o bem viver do rebanho, jamais tendo em vista um

16 Sobre a cultura escolar implantada pelos jesuítas na América-portuguesa sugere-se: HANSEN, João Adolfo. Ratio Studiorum e Política Católica Ibérica no século XVIII. In: VIDAL, Diana Gonçalves; HILSDORF, Maria Lúcia Spedo (Orgs.). Brasil 500 anos: Tópicas em História da Educação. São Paulo: Editora da Universidade de São Paulo, 2001, pp. 13-42, p. 13. 
benefício próprio. Seu benefício, ou seja, sua salvação nesse mundo vem justamente da qualidade de ser um bom pastor. O pastor é responsável pela manutenção da vida de suas "ovelhas". Quando elas se salvam, ele se salva (MOURA, 2007, p. 34).

Consideramos, ainda, que na narrativa de Gusmão foram mobilizados diferentes dispositivos e técnicas para regular o tempo e o espaço do sujeito infantil, modelar seu corpo através do controle de gestos e das condutas normalizadas. Nesse estudo, identificamos a organização de um padrão específico de comportamento familiar e social para o menino cristão. O modelo proposto impõe uma série de preceitos de condutas e de valores, que articulados em torno do pensamento religioso da época, constituem discursivamente um específico modo de ser sujeito infantil no espaço luso-brasileiro do final do século XVII.

Os efeitos das constantes vigilâncias e das repetidas punições como forma de se obter a correção, o uso dos bons costumes, o fortalecimento da alma, criaram certas moderações e tornaram o sujeito de "boas esperança', e também livra da "morte temporal" - uma ameaça constante que Gusmão traz da "morte repentina", ou seja, a incitação ao medo da possível morte imprevista.

Assim, a educação familiar, promovida discursivamente pela Igreja, não deveria simplesmente captar crianças/ovelhas para ampliar sua coleção de almas cristãs/rebanho. Mas, deveria, sobretudo, formar crianças dóceis, obedientes, moralizadas, conscientes da constante vigilância exercidas pelos pais sobre seus corpos ou, ainda pela onipresença divina, submissa aos castigos físicos e receptivas do constante amedrontamento das possíveis penas espirituais. Padecer a estas punições seria uma oportunidade da remissão de suas faltas.

\section{REFERENCIAS}

BLUTEAU, Raphael. Vocabulário portuguez e latino. Lisboa, na Officina de Pascoal da Sylva, 1716.

GUSMÃO, Alexandre de. Arte de crear bem os filhos na idade da puericia, Dedicada ao Minino de Belém, JESU Nazareno. Lisboa: Officina de Miguel Deslandes, 1685.

SILVA, Antonio de Moraes. Dicionario da Lingua Portugueza. Lisba: Typographia Lacerdina, 1789. 


\section{Obras consultadas}

CANDIOTTO, Cesar. A genealogia da ética de Michel Foucault. Educação e Filosofia, Uberlândia, v. 27, n. 53, p. 217-234, jan./jun. 2013.

CASTRO, Edgardo. Vocabulário de Foucault: um percurso pelos seus temas, conceitos e autores. Trad. Ingrid Muller Xavier. Belo Horizonte: Autêntica, 2009.

CHARTIER, Roger. A mão do autor e a mente do editor. São Paulo: Editora Unesp, 2014.

CONSTITUIÇÕES DA COMPANHIA DE JESUS e Normas Complementares. São Paulo: Loyola, 2004.

FISCHER, Rosa M. B. Foucault e o desejável conhecimento do sujeito. Educação e Realidade, Porto Alegre (RS), v. 24, n.1, p. 39-59, 1999.

FLECK, Eliane D.; DILMANN, Mauro. Escrita, prática de leitura e circulação de manuais de devoção entre Portugal e Brasil nos séculos XVIII e XIX. História, histórias, Brasília, vol. 2, n. 4, p. 44-60, 2014.

FOUCAULT, Michel. Vigiar e punir: a história da violência nas prisões. Petrópolis: Vozes, 1997.

GUSMÃO, Alexandre de. Arte de Criar bem os filhos na idade da puerícia - Dedicada ao Menino de Belém Iesu Nazareno. São Paulo: Martins Fontes, 2004 [1685].

MOURA, João Clemente A. Quaresma de. O poder na obra de Foucault e as estratégias do contemporâneo. Dissertação de Mestrado. 85 f. Pontifícia Universidade Católica do Rio de Janeiro, Rio de Janeiro, 2007.

REVEL, J. As práticas de civilidade. In: ARIÉS, Philippe. DUBY, Georges, D. História da vida privada: Do Renascimento ao Século das Luzes, V. 3. São Paulo: Companhia das Letras, 2009.

SOUZA, Lais Viena de. Má educação e maus exemplos: o discurso pedagógico/ moral do padre Alexandre de Gusmão S. J. (1629-1724). Anais do VIII Simpósio da Associação Brasileira de História das Religiões, 2006.

VENÂNCIO, Renato Pinto; Ramos, Jânia Martins. Apresentação. In: GUSMÃO, Alexandre de. Arte de Criar bem os filhos na idade da puerícia - Dedicada ao Menino de Belém Iesu Nazareno. VENÂNCIO, Renato Pinto \& RAMOS, Jânia Martins (org). São Paulo: Martins Fontes, 2004, p. 9-32. 


\section{Como citar este artigo:}

RIPE, Fernando. A exortação do poder pastoral na educação das crianças em um tratado de Alexandre de Gusmão, América Portuguesa (Século XVII). Revista on line de Política e Gestão Educacional, Araraquara, v.21, n.2, p. 522-541, maio-ago. 2017. Disponível em: <http://dx.doi.org/10.22633/rpge.v21.n.2.2017.9955>. ISSN: 1519-9029.

Submetido em: 07/06/2017

Aprovado em: 02/07/2017 